\title{
A historicidade da linguagem nas novas configurações familiares: um olhar jurídico
}

\author{
Adriana de Moraes Pereira Santos \\ Universidade do Vale do Sapucaí (UNIVÁS), Pouso Alegre, Minas Gerais, Brasil \\ adrianamoraes@adilsonralfadvocacia.com.br
}

DOI: $\underline{\text { http } / / d x . d o i . o r g / 10.21165 / e l . v 45 i 1.724 ~}$

\begin{abstract}
Resumo
O presente artigo objetiva discutir a maneira como os princípios constitucionais, a lei e as jurisprudências relacionadas às novas formas de família vêm sendo abordadas no âmbito das ciências jurídicas. Para isso, toma-se como lugar de investigação os postulados teóricos da Análise de Discurso de linha francesa e a Semântica Histórica da Enunciação, a fim de refletir sobre o funcionamento da linguagem jurídica, sobre o alcance ou as transformações que são produzidas, a partir dela, na constituição e posturas dos sujeitos ante as novas tendências relacionadas à igualdade de direitos entre homens, mulheres e homoafetivos, bem como compreender o modo como a materialidade da lei e a interpretação dos tribunais afetam a questão do casamento, da união estável e da guarda dos filhos ante aos novos arranjos familiares. Além de evidenciar como a lógica dos tribunais, manifestada em seus julgados, garante, materialmente, o exercício do Direito e legitima, valida as expressões vigentes na sociedade.
\end{abstract}

Palavras-chave: análise de discurso; semântica histórica da enunciação; família; novos arranjos familiares, lei.

\section{The language historicity in the new family settings: a legal view}

\begin{abstract}
The present paper aims to discuss about the way the constitutional principles, the law and the court precedents related to the new family models have been understood within legal science. For that, it is taken as the place of investigation, the studies of the French Discourse Analysis and the Historical Semantics of Enunciation, so that it is possible to reflect on how legal language works, on the reaching or transformations produced from it, on the constitution and the people's attitude facing new trends related to the equality of rights among men, women and homosexual couples, and also to understand how the materiality of the law and the interpretations at the courts influence the marriage, stable union and the children custody, as regards the new family organizations. In addition, it aims to show how the logic of the courts, manifested in their trials, significantly ensures the Law practice and legitimates the current expressions of the society.
\end{abstract}

Keywords: discourse analysis; historical semantics of enunciation; family; new family organizations; law.

\section{Introdução}

O presente artigo objetiva discutir a maneira como os princípios constitucionais, a lei e as jurisprudências relacionadas às novas concepções de família vêm sendo abordadas no âmbito das ciências jurídicas. Para isso, toma-se como lugar de 
investigação as ciências da linguagem, sobretudo, adotam-se os postulados teóricos da Análise do discurso de linha francesa. Pretende-se então refletir sobre o funcioname nto da linguagem jurídica, sobre o alcance ou as transformações que são produzidas a partir dela na constituição e posturas dos sujeitos ante as novas tendências relacionadas à igualdade de direitos entre homens e mulheres, entre homoafetivos. Busca-se ainda compreender o modo como a materialidade da norma jurídica e a sua interpretação nos tribunais, um discurso testado historicamente, afetam a questão do casamento, da união estável e da guarda dos filhos ante aos novos arranjos da família na contemporaneidade.

De acordo com Roudinesco (2003), em um primeiro momento, alicerçada e inteiramente submetida a uma autoridade patriarcal, a família tradicional (patriarcal) tem como fundamento único assegurar a transmissão de um patrimônio, nesse sentido, há nesse período o predomínio dos casamentos arranjados pelos pais, que não consideravam a vida sexual e afetiva dos cônjuges, uma vez que eles ainda eram menores de idade. No segundo momento (final do século XVI até meados do século $\mathrm{XX}$ ), a família é fundada na reciprocidade de sentimentos e na autoridade, que outrora era assegurada pelo pai, e passa a ser dividida com o Estado. No terceiro momento, a família dita contemporânea não se baseia somente em laços matrimoniais, mas sim em relações nem sempre duradouras, que se baseiam apenas em realizações sexuais. (ROUDINESCO, 2003, p.19).

Tais momentos, abordados pela autora acerca da família, são relevantes, pois evidenciam a importância de se refletir sobre como as relações sócio-históricas que se manifestam na/pela linguagem afetam as mudanças ocorridas no cerne desta instituição, que sempre garantiu a existência a e estruturação dos sujeitos.

\section{O discurso jurídico e a família no século XXI}

O discurso sólido da estrutura familiar, marcado pelas legislações, que se postava como guardião das tradições, do patrimônio, da transmis são e da circulação de riquezas, afrouxa-se ao longo da história e apresenta-se, neste novo milênio, muito mais fluído, muito mais flexível, muito mais liquefeito, uma vez que seus entes não se submetem mais às vontades de um Pai: tornaram-se "sujeitos desejantes", donos de seus dizeres e de suas vontades. E essa inversão de posturas faz com que o Direito se interesse, na atualidade, muito mais pela essência - o sujeito - do que pela forma - a família.

Com a elevação da pessoa ao centro da cena jurídica, tudo teve que ser repensado. Tradicionais institutos jurídicos perderam a força e o sentido. Houve uma verdadeira 'desconstrução' de valores jurídicos, sempre em direção à valorização da pessoa. Com isso compreendeu-se que não é possível pensar em Direito de Família sem pensar em dignidade, inclusão e cidadania. Consequentemente, não foi mais possível falar em ilegitimidade dos filhos ou de qualquer tipo de família. Todos os fillhos são legítimos e todas as famílias deverão ser reconhecidas pelo Estado. (FARIAS; ROSENVALD, 2015, prefácio)

Refletir acerca dos sentidos da família no século XXI é demonstrar que a práxis humana significa e produz sentido, uma vez que o homem por ser simbólico, por fazer uso e se constituir da/pela linguagem, é afetado pela história, pelo cruzamento de falas, dizeres e já ditos, que se materializam nas Constituições Brasileiras, no Direito de 
Familia, por que não dizer das Famílias e nas Jurisprudências que buscam dar sentidos e criar sentidos às atitudes e às escolhas dos entes familiares no decorrer da história da humanidade.

Se a ordem do simbólico antecede o sujeito, podemos dizer que é nesse mesmo "campo de linguagem" que se encontra o Direito como discurso, como um conjunto de práticas com ramificações políticas, sociais, morais, históricas e culturais entrelaçadas e reveladas em enunciados que concretizam a ideologia dominante de uma sociedade. Poderíamos dizer que, em princípio, o Direito se posta como um discurso "aparentemente neutro" capaz de apenas "registrar" os acontecimentos sociais, os discursos tradicionais e as preferências valorativas adotadas por uma sociedade.

Nesse sentido, o modo como o discurso jurídico desenvolve todo o arcabouço conceitual-legal que sustenta a ilusão constitutiva do sujeito, faz surgir, segundo Pêcheux (1997[1975], p.182, nota de rodapé 18), o sujeito-de-direito que se apresenta como "uma nova forma de assujeitamento", a forma "plenamente visível da autonomia".

O sujeito-de-direito é o portador de um nome, de direitos e obrigações jurídicas, é aquele sujeito que possui a prerrogativa de reclamar uma prestação assegurada pelo ordenamento jurídico e se encontra obrigado a efetivar uma prestação.

O Direito, enquanto sistema, interpela os sujeitos e fornece-lhes uma "realidade". O discurso jurídico aparenta possuir uma neutralidade que tenta garantir a estabilização dos sujeitos. Pressupõe uma noção instrumental-comunicativa-funcional da linguagem, e opera como se a linguagem fosse transparente, carente de materialidade própria. Esses traços podem ser observados nos dizeres de Bittar (2003, p. XVI- XVII):

O Direito é praticado por meio da comunicação, pois pressupõe a interaçãodos agentes, a vida em sociedade e a necessidade de regulamentação de condutas num determinado espaço. [...] O Direito como prática de linguagem, ou linguagens, na forja social, nada mais é que instrumento de intervenção do homem sobre o homem, e assim se apresenta, assim se manifesta, assim se faz [...]. O Direito enquanto retículo sócio-cultural e produto da comunhão de diversos valores sociais (organização, política, convívio, obediência, sobrevivência, trabalho...), temcomo uma de suas perspectivas a linguagem [sic]. É a linguagem assim uma de suas características.

Podemos dizer que um dos pressupostos essenciais do discurso jurídico é a comunicabilidade plena dos argumentos, e que as possíveis dificuldades ou os dissensos interpretativos poderão ser solucionados sempre a partir de uma nova interpretação esclarecedora e/ou pela validação interpretativa de uma autoridade. Por não entender a linguagem como transparente, seguindo a posição materialista e ratificando que o funcionamento de sentidos em um texto é atravessado por provocações sociais, impregnadas de memórias, de possibilidades de novas filiações, de futuridades e subjetividades que se entrelaçam, a forma atual de se ver e de se entender a família nos enunciados legais apresenta-se sobre novas concepções e arranjos ao compararmos as Constituições e legis lações Civis Brasileiras. 


\subsection{A Família nas legislações brasileiras}

Considerando as legislações brasileiras como cenas enunciativas, como um lugar formado por dizeres, podemos pensá-las como espaços singulares, que colocam em jogo e marcam o modo de pensar do "povo brasileiro" ao longo da história.

Assim sendo, ao colocarmos em evidência a historicidade da Família nas Constituições e Codificações brasileiras, podemos verificar em seus enunciados certa relação dialética existente entre os acontecimentos passados - determinados pelos valores coletivos e pelas instituições de poder - o movimentar do discurso tradicional, das preferências valorativas que ora contrastam, ora afirmam os ordenamentos jurídicos adotados por nossa sociedade.

Podemos averiguar que, no percorrer histórico das legislações brasileiras, não há um movimento retilíneo quanto aos sentidos da família, mas sim um movimento cíclico, uma disputa entre o discurso religioso e o discurso jurídico-político acerca do significar desta entidade.

Se tomarmos como ponto de partida a família brasileira à época do texto constitucional de 1824 , podemos notar a não existência de qualquer menção à família brasileira, somente havia a fixação das regras de sucessão do Poder Imperial ${ }^{1}$, visto que o liberalis mo da época não admitia a intervenção do Estado nos aspectos referentes aos indivíduos (OLIVEIRA, 2002,p. 32). Esse "não dito" na constituição, essa não presença de um dispositivo legal que norteasse o Direito das Famílias Brasileiras acabou sendo

\footnotetext{
1 Art. 105. O Herdeiro presumptivo do Império terá o Título de "Principe Imperial" e o seu Primogenito o de "Principe do Grão Pará" todos os mais terão o de "Principes". O tratamento do Herdeiro presumptivo será o de "Alteza Imperial" e o mesmo será o do Principe do Grão Pará: os outros Principes terão o Tratamento de Alteza.

Art. 106. 0 Herdeiro presumptivo, em completando quatorze annos de idade, prestará nas mãos do Presidente do Senado, reunidas as duas Camaras, o seguinte Juramento - Juro manter a Religião Catholica Apostolica Romana, observar a Constituição Política da Nação Brazileira, e ser obediente ás Leis, e ao Imperador.

Art. 107. A Assembléa Geral, logo que o Imperador succeder no Imperio, lhe assignará, e á Imperatriz Sua Augusta Esposa uma Dotação correspondente ao decoro de Sua Alta Dignidade.

Art. 108. A Dotação assignada ao presente Imperador, e á Sua Augusta Esposa deverá ser augmentada, vis to que as circumstancias actuaes não permittem, que se fixe desde já uma somma adequada ao decoro de Suas Augustas Pessoas, e Dignidade da Nação.

Art. 109. A Assembléa assignará tambem alimentos ao Principe Imperial, e aos demais Principes, desde que nascerem. Os alimentos dados aos Principes cessarão sómente, quando elles sahirem para fóra do Imperio.

Art. 110. Os Mestres dos Principes serão da escolha, e nomeação do Imperador, e a Assembléa lhes designará os Ordenados, que deverão ser pagos pelo Thesouro Nacional.

Art. 111. Na primeira Sessão de cada Legislatura, a Camara dos Deputados exigirá dos Mestres uma conta do estado do adiantamento dos seus Augustos Discipulos.

Art. 112. Quando as Princezas houverem de casar, a Assembléa lhes as signará o seu Dote, e com a entrega delle cessarão os alimentos.

Art. 113. Aos Principes, que se casarem, e forem residir fóra do Imperio, se entregará por uma vez sómente uma quantia determinada pela Assembléa, com o que cessarão os alimentos, que percebiam.

Art. 114. A Dotação, Alimentos, e Dotes, de que fallam os Artigos antecedentes, serão pagos pelo Thesouro Publico, entregues a um Mordomo, nomeado pelo Imperador, com quem se poderão tratar as Acções activas e passivas, concernentes aos interesses da Casa Imperial.

Art. 115. Os Palacios, e Terrenos Nacionaes, possuidos actualmente pelo Senhor D. Pedro I, ficarão sempre pertencendo a Seus Successores; e a Nação cuidará nas acquisições, e construcções, que julgar convenientes para a decencia, e recreio do Imperador, e sua Familia.
} 
"suprido" pelas Ordenações Filipinas, que, juntamente com a Constituição do Império, estabeleceu como oficial a religião Católica e, por consequência, o casamento quando celebrado pela autoridade católica. (AZEVEDO, 2002, p. 123-124).

Coube à igreja, amparada pelo Direito Canônico, a incumbência de cuidar da matéria casamento, e da filiação legítima, já que a CF de 1824 não admitia em seus aportes legais ressaltar tal aparato.

No âmbito do Direito Canônico, é a família considerada pelas Escrituras como entidade de direito divino. Para a Igreja, a família tem origem exclusivamente no cas ame nto, ins tituição criada por De us e elevada à categoria de sacramento, com a finalidade de santificar a união indissolúvel do homem e da mulher, vis ando não à satisfação da concupis cência pe locongressose xual, mas também, e principalmente, à procriação e educação da prole. (GOMES, 1993, p. 105-118, grifo meu)

Notamos que o sentido da família, neste período, aparece como sinônimo de entidade divina, sacramento, entidade que santificava a união entre um homem e uma mulher, além de visar principalmente a procriação e ser o casamento somente celebrado por uma autoridade católica. E que nossa doutrina antiga em direito familiar foi determinada pela religiosidade.

Tal rigidez na forma de se pensar a realização e a consagração do casamento ocasionou diversas discussões no âmbito social da época, por não ser a religião católica a única praticada no Brasil e não haver o reconhecimento do matrimônio entre as pessoas que não professavam o catolicismo. Como o discurso jurídico não pôde se apresentar como discurso descontextualizado, mas sim como um discurso tecido, confeccionado no seio da vida social, para amenizar os conflitos existentes entre os sujeitos pertencentes às outras religiões, ocorreu a publicação da Lei 1.144 de setembro de 1861 que "[...] deu efeitos civis aos casamentos religiosos realizados pelos não católicos desde que estivessem devidamente registrados". Porém, somente por meio do Decreto $\mathrm{n}^{\circ} 181$ de $1890^{2}$ o casamento civil tornou-se válido no Brasil.

Ainda de caráter não intervencionista, a Constituição Republicana de 1891 mantém os ideais acerca do casamento e acrescenta um único artigo, o artigo $72 \S^{\circ}$ que pertencia ao bojo à Declaração de Direitos cujos enunciados mencionavam: "a república só reconhece o casamento civil, cuja celebração será gratuita".

Observa-se, no entanto, um remodelar no sentido de família, devido a uma ação política desta Constituição ao instituir a laicização do Brasil e marcar a vinculação do casamento civil nos dizeres constitucionais. Tal mudança nos princípios constitucio nais força a elaboração do Código Civil de 1916, Lei 3.701, de 01.01.1916, que deu aparato legal às questões familiares da época.

Conforme esse Código, a família devia ser constituída exclusivamente pelo matrimônio. Há na visão dele uma estreita e discriminatória visão da família, limitandoa ao grupo originário do casamento e o impedimento da dissolução deste. Apresentava distinções entre seus membros e trazia qualificações discriminatórias às pessoas unidas

\footnotetext{
${ }^{2} \mathrm{O}$ casamento civil, único válido por termos do Art. 108 do Decreto $\mathrm{n}^{\circ} 181$ de janeiro último, precederá sempre as cerimônias religiosas de qualquer culto com que desejem solenizá-las os nubentes. O ministro de qualquer confissão que celebrar as cerimônias religios as do casamento antes do ato civil será punido com seis meses de prisão e multa correspondente à metade do tempo.
} 
sem casamento e aos filhos oriundos de tais relações. As referências feitas aos vínculos extramatrimoniais e aos filhos ilegítimos eram punitivas e serviam para excluir direitos (DIAS, 2007, p. 30).

É interessante evidenciar aqui o modo como o discurso da lei aparece ressignificando o sentido da família para a época, que, ao marcar certa transparência, coloca o sentido da família como desprovido de religiosidade e abastecido de poder legal, como se apenas tal condição bastasse para a época.

Já as Constituições Brasileiras de 1937, 1946 e 1969 trouxeram em seu corpo textual um sentido único de que o casamento era a única forma de se constituir uma família. Porém, para conseguir manter a estabilidade social, pois a sociedade se movimenta, a CF de 1946 dedica um capítulo inteiro a esta instituição e, sob sua regência edita a Lei 4.121, de 27.08.1962, intitulada de "Estatuto da Mulher Casada", que mesmo ainda possuindo características patriarcais - atenuou a condição da mulher casada, conferindo-lhe parcial independência em seus atos. (NAHAS, 2008, p.78). E mais tarde a Súmula 380 de 11.05.1964 que dizia ser "Comprovada a existência da sociedade de fato entre os concubinos", tornando "cabível a sua dissolução judicial, com a partilha do patrimônio adquirido pelo esforço comum". (NAHAS, 2008, p.7879).

É na vigência da Constituição de 1967, com a Emenda Constitucional n ${ }^{\circ} 9$ de 1977, que realmente se admitiu indissolubilidade do casamento, através da Lei Ordinária Federal 6.515 de 1977, denominada "Lei do Divórcio". De acordo com Maria Berenice Dias (2007, p.30), "a instituição do divórcio (EC 9/1977 e L 6515/1977) acabou com a indissolubilidade do casamento, eliminando a ideia da família como instituição sacralizada", além de permitir a realização de um segundo casamento.

\subsection{As Famílias na Constituição Federal de 1988}

As crescentes modificações de ordem social e econômica durante o século XX, como a Revolução Industrial, seguida pela Revolução Tecnológica, o maior envolvimento da mulher em atividades externas, a liberação sexual, a institucionalização do divórcio, a constituição de relações íntimas e informais mesmo por pessoas já casadas, a obtenção instantânea e abundante de informações acerca das mais variadas tendências mundiais por meio da internet, as relações sexuais iniciadas em idade cada vez mais tenra e os novos arranjos em contexto familiar impulsionaram mudanças drásticas nas relações jurídicas, principalmente no que se refere às famílias, já que todos esses elementos não encontravam amparo nos dizeres da legislação idealizada ao findar do século XIX - que limitava a família ao casamento, dava prevalência aos direitos do chefe de família sobre seus demais integrantes e que pregava a desigualdade na ordem da filiação.

Tais acontecimentos instigaram nossas leis a galgarem por novos paradigmas a fim de "suprirem" as atuais modelagens da nova era das relações familiares que clamava por uma mudança na mentalidade do aplicador da norma jurídica que se encontrava norteado por uma norma constitucional e cívica baseada no modelo patriarcal e hierarquizado.

Foi, então, com o advento da Constituição de 1988 que se pôde verificar mudanças um tanto quanto significativas relacionadas à proteção à família. $\mathrm{O}$ 
constituinte brasileiro, norteado pela tendência da democratização, igualdade, dignidade, pluralismo e aparente ausência de discriminação, elaborou o caput do art. $226^{3}$ da Constituição Federal de 1988 concedendo à família especial proteção do Estado, sem apresentar à instituição um conceito ao excluir, deste caput, a menção ao matrimônio.

A referência à família como base da sociedade foi mantida, porém a $\mathrm{CF} / 88$ não determinou modelos específicos, pois face à doutrina constitucional dos direitos fundamentais que valoriza a dignidade da pessoa humana, o Estado não pôde mais admitir apenas um modelo de organização familiar, coube ao direito regular os fatos sociais para legitimar a igualdade e a liberdade que têm os sujeitos de organizarem o seu núcleo essencial de afeto e solidariedade.

Lapidando o sistema anterior, que só reconhecia a sociedade biparental - filhos de pai e mãe - a Constituição Federal de 88 reconheceu a família monoparental, entendeu como entidade familiar a comunidade formada por qualquer um dos pais e seus descendentes e assegurou a proteção às mães solteiras, aos pais solteiros, à comunidade de pais ou mães divorciados e eventuais filhos, bem como as famílias instituídas por inseminação artificial, produção independente etc. Assim sendo, a família assume aos dizeres de Luiz Edson Fachin (1999, p. 303-304) uma dimensão renovada, eudemonista, firmada na igualdade, na direção diárquica e na nãodiscriminação.

Podemos verificar que o Direito de Familia tem caminhado no sentido de reconhecer que a dimensão simbólica, muito mais do que o meramente biológico, constitui a base da família. Essa característica fora exaltada em nossa legislação pelo

\footnotetext{
${ }^{3}$ Art. 226. A família, base da sociedade, tem especial proteção do Estado.

$\S 1^{\circ} \mathrm{O}$ casamento é civil e gratuita a sua celebração.

$\S 2^{\circ} \mathrm{O}$ casamento religioso tem efeito civil, nos termos da lei.

$\S 3^{\circ}$ Para efeito da proteção do Estado, é reconhecida a união estável entre o homem e a mulher como entidade familiar, devendo a lei facilitar sua conversão em casamento.

$\S 4^{\circ}$ Entende-se, também, como entidade familiar a comunidade formada por qualquer dos pais e seus descendentes.

$\S 5^{\circ}$ Os direitos e deveres referentes à sociedade conjugal são exercidos igualmente pelo homem e pela mulher.

$\S 6^{\circ} \mathrm{O}$ casamento civil pode ser dissolvido pelo divórcio, após prévia separação judicial por mais de um ano nos casos expressos em lei, ou comprovada separação de fato por mais de dois anos. $\$ 7^{\circ}$ Fundado nos princípios da dignidade da pessoa humana e da paternidade responsável, o planejamento familiar é livre decisão do casal, competindo ao Estado propiciar recursos educacionais e científicos para o exercício desse direito, vedada qualquer forma coercitiva por parte de instituições oficiais ou privadas. $\S 8^{\circ} \mathrm{O}$ Estado assegurará a assistência à família na pessoa de cada um dos que a integram, criando mecanis mos para coibir a violência no âmbito de suas relações.
} 
atual Código Civil Brasileiro - CCB, ao regular, por exemplo, o instituto da adoção (art. 1618 e seguintes) ${ }^{4}$ e ao dispor sobre a inseminação artificial (art. 1597 e incisos) ${ }^{5}$.

$\mathrm{O}$ ato da adoção, por exemplo, gera o parentesco civil entre adotante e adotado. O filho adotivo equipara-se ao consanguíneo sob todos os aspectos, ficando sujeito ao poder familiar dos adotantes, extinguindo, portanto, o poder familiar dos pais biológicos (art. 1635, IV) ${ }^{6}$ e atribui a situação de filho ao adotado, "desligando-o de qualquer vínculo com os pais e parentes consanguíneos" (art. 1626) (GONÇALVES, 2005, p. 350).

O Parágrafo $6^{\circ}$ do art. 227 da Constituição Federal de 1988, ao determinar que "os filhos havidos ou não da relação de casamento, ou por adoção, terão os mesmos direitos e qualificações, proibidas quaisquer designações discriminatórias em relação à filiação", deixa em evidência dois dos princípios que regem o direito de família: (i) o princípio do respeito à dignidade da pessoa humana que constitui a base da entidade familiar tendo como parâmetro a afetividade, o desenvolvimento de todos os seus membros, e (ii) o princípio da igualdade jurídica de todos os filhos, já que não faz nenhuma distinção entre os filhos legítimos, naturais e adotivos, como prezava o artigo 332 do antigo Código Civil Brasileiro de 1916 ao dispor que o parentesco "era legítimo ou ilegítimo, segundo precedia ou não de casamento, e natural ou civil conforme resultasse de consanguinidade ou adoção.".

Há outros artigos do atual Código Civil Brasileiro que, comparado aos artigos do Código Civil Brasileiro de 1916, expõem que a estrutura familiar deve ser embasada no elemento psíquico e afetivo, para que haja uma adequada representação de funções no núcleo da família.

Tomando como base esse raciocínio, por considerar que a união entre pessoas do mesmo sexo constitui uma unidade familiar, por aplicarem, de forma análoga, as mesmas regras previstas para a união estável, foi pronunciado em 2008, pelo Supremo Tribunal Federal (STF) pela primeira vez, o reconhecimento das uniões homoafetivas como entidades familiares merecedoras de proteção estatal. Acerca do assunto

\footnotetext{
${ }^{4}$ Para um melhor entendimento de nossa comparação, coloco em evidência os artigos do Código Civil Brasileiro referente à adoção: Art. 1.621. "A adoção depende de consentimento dos pais ou dos representantes legais, de quem se deseja adotar, e da concordância deste se contar mais de doze anos". Art. 1.626. "A adoção atribui a situação de filho ao adotado, desligando-o de qualquer vínculo com os pais e parentes cons anguíneos, salvo quanto aos impedimentos para o cas amento. Parágrafo único. Se um dos cônjuges ou companheiros adota o filho do outro, mantêm-se os vínculos de filiação entre o adotado e o cônjuge ou companheiro do adotante e os respectivos parentes". Art. 1.627. "A decisão confere ao adotado o sobrenome do adotante, podendo determinar a modificação de seu prenome, se menor, a pedido do adotante ou do adotado". Art. 1.628. "[...] As relações de parentesco se estabelecem não só entre o adotante e o adotado, como também entre aquele e os descendentes deste e entre o adotado e todos os parentes do adotante". (negrito meu)

5 Quanto à inseminação artificial, nosso CCB discorre: Art. 1.597. "Presumem-se concebidos na constância do casamento os filhos: [...] IV - havidos, a qualquer tempo, quando se tratar de embriões excedentários, decorrentes de concepção artificial homóloga; V - havidos por inseminação artificial heteróloga, desde que tenha prévia autorização do marido. (grifo meu)

${ }^{6}$ A equiparação do parentesco civil ao parentesco consanguíneo - Art. 1.635. "Extingue-se o poder familiar: IV - pela adoção"; (negrito meu)

${ }^{7}$ Art. 1.626. "A adoção atribui a situação de filho ao adotado, desligando-o de qualquer vínculo com os pais e parentes consanguíneos, salvo quanto aos impedimentos para o casamento. Parágrafo único. Se um dos cônjuges ou companheiros adota o filho do outro, mantêm-se os vínculos de filiação entre o adotado e o cônjuge ou companheiro do adotante e os respectivos parentes" (negrito meu).
} 
encontramos controvérsias na doutrina brasileira, uma vez que parcela dela adotava, ou melhor, ainda adota, um posicionamento mais conservador a esse respeito, como Carlos Alberto Gonçalves ${ }^{8}$ e Maria Helena Diniz ${ }^{9}$, por sustentarem que a diversidade de sexos é requisito natural da constituição de uma família, chegando mesmo a expressar "inexistentes as uniões homossexuais", estando a matéria excluída do direito de família, devendo ser analisada como contrato de sociedade, gerando assim apenas efeitos de caráter obrigacional.

Postando-se de forma diferente, Lenza (2010, p. 952, grifo do autor) expõe:

Com o máximo respeito e profunda admiração que temos pelo ilustre professor com a devida vênia, não concordamos com esse posicionamento. Deve ser feita uma interpretação mais ampla do art. 226, $\S 3^{\circ}$ (que discorre sobre a união estável entre homem e mulher) à luz do caput, que prestigia a proteção à família, e, especialmente, do princípio da dignidade da pessoa humana (art. $1^{\circ}$, III, da CF/88). Não temos dúvida de que o direito tem de evoluir para disciplinar a realidade social das uniões homoafetivas, assegurando o direito à herança, previdência, propriedade, sucessão e, quem sabe, no futuro, de acordo com evolução da sociedade, de adoção de crianças e qualquer outro direito assegurado à união estável como entidade familiar.

Nessa mesma visão, Maria Berenice Dias (2001, p. 97, grifo nosso) argumenta:

[...] impositivo reconhecer a existência de um gênero de união estável que comporta mais de uma espécie: união estável heteroafetiva e união estável homoafetiva. Ambas me recem ser reconhecidas como entidade familiar. Havendo consciência duradoura, pública e contínua entre duas pessoas, estabelecida com o objetivo de constituição de família, mister reconhecer a existência de uma união estável. Independente do sexo dos parceiros, fazem jus à mesma proteção.

E finalmente, em 2011, o Supremo Tribunal Federal legalizou o reconhecime nto desta união. Fato que abriu precedência à discussão de uma legislação acerca dos direitos matrimoniais e ocasionou várias e constantes polêmicas instigando a apresentação de dois projetos de lei: o Projeto de Lei (PL 6.583/13) denominado Estatuto da Familia relatado pelo deputado Ronaldo Fonseca (PROS-DF), que define família como o núcleo formado a partir da união entre homem e mulher, por meio de casamento, união estável ou comunidade formada pelos pais e seus descendentes ${ }^{10}$; e Projeto de Lei Suplementar (PLS 470/13) intitulado como Direito das Famílias que tramita no Senado e reconhece a relação homoafetivas como entidade familiar ao rever o instituto da união estável e ampliar o conceito de casamento.

Assim, podemos observar que nosso ordenamento jurídico se encontra diante da seguinte discussão: Deve-se resguardar e dar proteção a essa "nova família" que, mesmo constituída de fato, não recebe qualquer previsão legal ou garantias que resguardam a primeira família? E como tratar os efeitos e consequências diretas causadas por elas em nosso ordenamento como um todo, uma vez que elas existem e coexistem muito além de uma construção textual.

\footnotetext{
${ }^{8}$ GONÇALVES, Carlos Alberto. Direito Civil Brasileiro: direito de família. São Paulo: Saraiva, 2005. v. VI, p.544.

${ }^{9}$ DINIZ, Maria Helena. Curso de Direito civil Brasileiro. v. 5: direito de família. 22. ed. rev. e atual. de acordo com a Reforma do CPC. São Paulo: Saraiva, 2007. p. 368.

10 A definição é a mesma enunciada no Artigo 226 da Constituição Federal de 1988.
} 
Se no Código Civil de 1916 a família se postava matrimonializada, patriarcal, hierarquizada, heteroparental, biológica, unidade de produção e reprodução, e de caráter institucional; agora, com o advento do Código Civil de 2002 encontra-se pluralizada, democrática, igualitária, hetero, homo, ou multiparental, biológica ou socioafetiva, e com caráter instrumental.

\section{Conclusão}

Podemos concluir então que esses "acontecimentos políticos" que camuflam os sentidos de uma expressão cuja constituição se encontra na relação integrativa, de forma não fragmentada, de um enunciado enquanto elemento de um texto, no caso, as constituições e codificações civis brasileiras - é que a "família" - se significa - forma uma teia de sentidos ora estabilizados, ora apagados, ora silenciados, ora ressignificados.

Podemos notar também que o discurso jurídico, por possuir, como dissemos, uma "comunicabilidade" natural entre os aspectos costumeiros/particulares da realidade "empírica", "imediata" e o caráter abstrato/universal do discurso da lei, deve ser ao mesmo tempo "suficientemente rígido" e "suficientemente flexível" para ora regular através da autoridade da Lei (universal) todos os fatos indeterminados, ora poder abrangê-los todos. E isso transmite-nos a sensação de que podemos nos apoiar na lei positivada para solucionar todos os problemas e conflitos existentes no nosso relacionar com o outro. Mesmo que alguma coisa escape à lei escrita, há sempre o que pode ser suprido com a utilização do "bom senso" pelo aplicador da lei, termo que oscila ou condensa, ao mesmo tempo, significações, conotações advindas da vivência humana, que de certa forma nos revela o fundo religioso do "senso comum" que circunda toda sociedade.

\section{REFERÊNCIAS}

ALTHUSSER, L. Ideologia e aparelhos ideológicos do Estado. Lisboa: Presença/ Martins Fontes, 1980[1970]. 122 p.

AZEVEDO, Á. V. Estatuto da família de fato. 2. ed. São Paulo: Atlas, 2002. 661 p.

BITTAR, E. C. B. Linguagem Jurídica. 2. ed. São Paulo: Saraiva, 2003. 387 p.

COSTA, C. C. P. M. (org.). O novo Código Civil comparativo. Rio de Janeiro: América Jurídica, 2003.148 p.

DIAS, M. B. União homossexual: o preconceito e a Justiça, 2001. 304 p.

Manual de Direito da Família. 4. ed., rev., atual. e ampl. São Paulo: Revista dos Tribunais, 2007. 608 p.

DINIZ, M. H. Curso de Direito Civil brasileiro. v. 5: direito de família. 22. ed. rev. e atual de acordo com a Reforma do CPC. São Paulo: Saraiva, 2007. 773 p.

Compêndio de Introdução à Ciência do Direito. 19. ed. rev. e atual. São Paulo: Saraiva, 2008. 591p.

FACHIN, L. E. Elementos críticos do direito de família. Rio de Janeiro: Renovar, 1999. $346 \mathrm{p}$. 
FARIAS, C.; ROSENVALD, N. Curso de Direito Civil: Familias. v. 6. 7. ed. rev. ampl. e atual. São Paulo: Atlas, 2015.1024 p.

GOMES, L. R. de F. O casamento no Direito brasileiro - aspectos diante da Constituição Federal. Revista Forense, v. 323, p. 105-118, 1993.

GONÇALVES, C. R. Direito civil brasileiro. v. VI: direito de família. São Paulo: Saraiva, 2005. 728 p.

LENZA, P. Direito Constitucional Esquematizado. 14. ed. rev., atual. e ampl. São Paulo: Saraiva, 2010. 1024 p.

MONTEIRO, W. de B. Curso de Direito Civil. 27. ed. São Paulo: Saraiva, 1989[1910]. $323 \mathrm{p}$.

NAHAS, L. F. União Homossexual: Proteção Constitucional. Curitiba: Juruá, 2008. $154 \mathrm{p}$.

NUNES, R. Manual de Introdução ao Direito: com exercícios para sala de aula e lições para casa. 6. ed. ver. ampl. e atual. São Paulo: Saraiva, 2005. 392 p.

OLIVEIRA. J. S. Fundamentos Constitucionais do Direito de Família. São Paulo: RT, 2002. 384 p.

ORLANDI, E. P. Terra à Vista. São Paulo: Cortez Editora, 1990. 260 p.

Gestos de leitura: da história no discurso. Campinas: Editora da UNICAMP, 1994. $277 \mathrm{p}$.

Interpretação: autoria, leitura e efeitos do trabalho simbólico. Petrópolis: Vozes, 1996. $160 \mathrm{p}$.

. Análise de discurso: princípios e procedimentos. Campinas: Pontes, 1999. 98

p.

PEREIRA, R. da C. Direito de Família: uma abordagem Psicanalítica. Belo Horizonte: Del Rey, 1997. 200 p.

PÊCHEUX, M. Ler o arquivo hoje. In. Gestos de leitura: da história no discurso. Campinas: Editora da UNICAMP, 1994. 277 p.

. Semântica e Discurso. Tradução brasileira de Les vérités de la Palice. 3. ed. Campinas: Editora da UNICAMP, 1997[1975]. 317p.

O discurso: Estrutura ou acontecimento. Tradução de Eni Puccinelli Orlandi.

2. ed. Campinas: Pontes, 1997[1983]. 66 p.

PLON, M. Análise do discurso (de Michel Pêcheux) vs. análise do inconsciente. In: INDURSKY, F.; FERREIRA, M. C. L. (org.). Michel Pêcheux e a análise do discurso: uma relação de nunca acabar. São Carlos: Claraluz, 2005. 302 p.

RODRIGUES, S. Comentários ao Código civil. Parte especial: direito de família. v. 17 (arts. 1511 a 1590) / Silvio Rodrigues; coord. Antônio Junqueira de Azevedo. São Paulo: Saraiva, 2003. 214 p.

Comentários ao Código civil. Parte especial: direito de família. v. 18 (arts. 1591 a 1710) / Sívio Rodrigues; coord. Antônio Junqueira de Azevedo. São Paulo: Saraiva, 2003. 433 p. 
ROUDINESCO, E. A família em desordem. Rio de Janeiro: Jorge Zahar, 2003. 199 p.

Recebido em: 04/10/2015

Aprovado em: 18/08/2016 